Int. J. Electrochem. Sci., 11 (2016) $4470-4496$

International Journal of

ELECTROCHEMICAL

SCIENCE

www.electrochemsci.org

Review

\title{
Nutritional and Methodological Perspectives of Zinc Ions and Complexes - Physiological and Pathological States
}

\author{
Jorge Molina-López ${ }^{1,2}$, Elena Planells del Pozo ${ }^{1,2}$, Daniela Ioana Florea ${ }^{1,3}$, Carlos Fernandez ${ }^{4}$, \\ Bartolome Quintero Osso ${ }^{5}$, Marta Zalewska, Sona Krizkova ${ }^{7,8}$, Zbynek Heger ${ }^{7,8}$, Rene Kizek ${ }^{7,8}$ and \\ Vojtech Adam ${ }^{7,8, *}$
}

${ }^{1}$ Institute of Nutrition and Food Technology, Biomedical Research Centre, University of Granada, E18071 Granada, Spain, European Union

${ }^{2}$ Department of Physiology, Faculty of Pharmacy, University of Granada, E-18071 Granada, Spain

${ }^{3}$ Moorfields Eye Hospital, London EC1V 2PD, United Kingdom, European Union

${ }^{4}$ School of Pharmacy and Life Sciences, Robert Gordon University, Garthdee Road, Aberdeen AB10

7GJ, United Kingdom, European Union

${ }^{5}$ Department of Physical Chemistry, Faculty of Pharmacy, University of Granada, E-18071 Granada, Spain, European Union

${ }^{6}$ Department of Biomedical and Environmental Analysis, Faculty of Pharmacy, Wroclaw Medical University, Borowska 211, 50-556 Wroclaw, Poland, European Union

${ }^{7}$ Department of Chemistry and Biochemistry, Mendel University in Brno, Zemedelska 1, CZ-613 00 Brno, Czech Republic, European Union

${ }^{8}$ Central European Institute of Technology, Brno University of Technology, Technicka 3058/10, CZ61600 Brno, Czech Republic, European Union

*E-mail: vojtech.adam@mendelu.cz

doi: $10.20964 / 2016.06 .38$

Received: 8 July 2015 / Accepted: 3 April 2016 / Published: 4 May 2016

Zinc, an essential element playing crucial roles in numerous physiological, but also pathological processes, is still one of the most studied elements. The main importance of this metal is especially based on the structural role of zinc ions in many proteins including the transcription factors, antioxidant enzymes, and metallothioneins. Due to the role of zinc in many crucial physiological processes, its homeostasis must be intensively controlled. The controlling mechanisms are based especially on the zinc transporters and low-molecular proteins metallothioneins (MT). Zinc deficiency has been related with different state of diseases. Here, we primarily aim our attention to zinc and nutrition reviewing the whole process from intake to determination of this metal. The function of zinc ions in proteins with particular emphasis to oxidative stress is discussed followed by intake mechanisms and the role of zinc ions in both physiological and pathological processes. Finally, we summarized the assays used for detection of zinc in complex biological matrices. 
Keywords: Zinc; biomarker; nutrition; health; disease; metallothionein; spectroscopy

\section{FULL TEXT}

(C) 2016 The Authors. Published by ESG (www.electrochemsci.org). This article is an open access article distributed under the terms and conditions of the Creative Commons Attribution license (http://creativecommons.org/licenses/by/4.0/). 